\title{
Estrutura e dinâmica da cafeicultura em Minas Gerais
}

\author{
Alessandro de Assis Santos Oliveira ${ }^{1}$ \\ Marília Fernandes Maciel Gomes ${ }^{2}$ \\ José dos Santos Luis Rufino3 \\ Aziz Galvão da Silva Júnior4 \\ Sebastião Teixeira Gomes 5
}

Resumo: Este artigo teve como objetivo identificar e analisar a dinâmica de crescimento da cafeicultura em Minas Gerais e em duas regiões do estado tipicamente produtoras - Sudoeste e Cerrado. O referencial teórico utilizado baseia-se na teoria de inovação induzida. O modelo analítico é o denominado Shift-Share, que permite decompor as fontes de crescimento nos efeitos área, rendimento, localização geográfica e composição, a fim de encontrar os fatores responsáveis pelo crescimento (ou queda) da produção. Os resultados apresentados indicam que existem diferenças nos fatores que determinam o crescimento da produção de café na região mais tradicional (Sudoeste) comparada à região relativamente mais moderna (Cerrado). Assim, pode-se salientar que programas e políticas que visam o desenvolvimento agrícola de determinadas regiões devem levar em consideração as especificidades destas, de forma a estimular atividades e práticas agrícolas segundo suas necessidades e particularidades, gerando o melhor impacto possível para as mesmas.

Palavras-chave: café do Cerrado; café do Sudoeste; fontes de incremento da cafeicultura.

\footnotetext{
1 Mestrando em Economia Aplicada (bolsista do CNPq). Universidade Federal de Viçosa - Departamento de Economia Rural. E-mail: alessandroassiufv@yahoo.com.br.

2 Professora do Departamento de Economia Rural, Universidade Federal de Viçosa (Dra. em Economia Rural). E-mail: mfmgomes@ufv.br.

3 Pesquisador da Embrapa Café. E-mail: jlsrufino@vicosa.ufv.br.

4 Professor do Departamento de Economia Rural, Universidade Federal de Viçosa (PhD em Administração Rural).E-mail: aziz@ufv.br.

5 Professor do Departamento de Economia Rural, Universidade Federal de Viçosa (Dr. em Economia). E-mail: stg@vicosa.ufv.br.
} 


\title{
Structure and dynamics of coffee growing in Minas Gerais, Brazil
}

\begin{abstract}
This article aims to identify and analyze the growth dynamics of the coffee crop in Minas Gerais and in two traditional producers of the State's Southwest and Savannah regions. The theoretical framework used is based on the theory of induced innovation. The analytic model is denominated "Shift-Share", which allows decomposing growth sources in affected areas, yield, geographical location and composition, in order to find the factors responsible for the growth (or fall) of production. The results indicate that there are differences in the factors that determine the growth of coffee production in the most traditional area (Southwest) compared to the relatively more modern area (Savannah). Therefore, it can be pointed out that developing programs and policies in certain agricultural areas should take into consideration their specific characteristics in order to stimulate activities and practices that can generate the best possible results for them.
\end{abstract}

Key words: Savannah coffee; Southwestern coffee; sources of increment on coffee growing.

JEL: O13

\section{Introdução}

A partir de 1960, a agricultura brasileira experimentou contínuo processo de modernização, caracterizado por alterações na política agrícola e criação de programas econômicos para o setor. Em Minas Gerais, as mudanças foram similares às ocorridas no Brasil, e o resultado de todo esse processo foi uma agricultura moderna, com novas formas de produção, de distribuição da terra, de composição da força de trabalho, com maior produtividade, com baixos custos de produção e competitiva no mercado internacional. Diante dessa nova realidade, observa-se que diferentes regiões, dotadas de uma disponibilidade diversificada de fatores de produção e habilidades de trabalho e de gestão, enfrentam diferentes dinâmicas de crescimento, porém em uma mesma cadeia produtiva.

Dentro dessa perspectiva também se insere a cadeia produtiva do café, principal produto da agropecuária mineira, que se caracteriza por apresentar inúmeras organizações, instituições e centros de pesquisa que conduzem o desenvolvimento, o controle e o aperfeiçoamento da atividade cafeeira no estado. Santos (2005) afirma que a cafeicultura mineira apresenta renovação e ampliação de suas lavouras em todas as regiões produtoras. Segundo a autora, essas regiões apresentam diferentes características na estrutura produtiva, nas propriedades, nos sistemas de manejo, na capacidade de produção e na composição do parque cafeeiro. 
Desse modo, partindo das informações supramencionadas, torna-se importante descrever as alterações na cafeicultura mineira, com destaque para a identificação de suas principais fontes de crescimento e das possíveis diferenças entre as suas principais regiões produtoras: Sudoeste e Cerrado.

A escolha dessas regiões justifica-se pela existência de programas de desenvolvimento da cafeicultura diferenciados, ou seja, a região Sudoeste é entendida como área de abrangência da ADEBRAS (Agência de Desenvolvimento Sustentável do Sudoeste de Minas Gerais). Essa instituição tem como objetivo promover o desenvolvimento regional, com transformações produtivas, eqüidade social e sustentabilidade ambiental. Para alcançar seus propósitos, a agência tem o papel de representar econômica e socialmente a região em rede de cooperação e parceria, visando agregar esforços no intuito de potencializar resultados, respeitando as orientações das entidades e federações pertinentes.

A região produtora de café do Cerrado Mineiro é demarcada, para fins deste estudo, como área de abrangência do CACCER (Conselho das Associações dos Cafeicultores do Cerrado). Esse conselho é uma ONG (organização não-governamental) cujos objetivos são promover a cafeicultura da região, fomentar linhas de pesquisa e coordenar ações políticas e de marketing.

Outro ponto preponderante para avaliação dessas regiões é o fato de elas apresentarem diferenças em seu processo produtivo e no período de tempo em que cultivam café. O Cerrado Mineiro, que iniciou sua produção em tempos recentes, é uma importante região produtora de café irrigado que apresenta o maior índice de mecanização das operações e a maior média de produtividade do país: em torno de 23,83 sacas/hectares. Já o Sudoeste destaca-se por ser a região mais tradicional do estado, e todos os municípios que a constituem são produtores de café.

Ao comparar a composição da produção de café entre as regiões produtoras em Minas Gerais, é possível definir certo padrão de modernização agrícola, isto é, determinar onde está concentrado o maior uso de tecnologias, identificar as diferenças nas produtividades parciais das regiões produtoras, determinar as implicações desses fatores para as regiões e para a cafeicultura mineira e, finalmente, atestar a relação entre a modernização e as mudanças estruturais observadas. Nesse sentido, a realização deste trabalho se faz importante uma vez que fornece contribuição adicional aos estudos relativos à modernização e à composição da agricultura brasileira.

As transformações ocorridas na cafeicultura mineira também é tema abordado em outros trabalhos, tais como o de Gomes e Rosado (2005), que estudam as mudanças ocorridas no comportamento produtivo desse setor, e o de Santos (2005), que avalia o impacto da produção e processamento do café na economia mineira. 
Sendo assim, para maior compreensão do tema abordado, o objetivo deste trabalho foi identificar e analisar a dinâmica de crescimento da cafeicultura no estado de Minas Gerais, com destaque para as regiões Sudoeste e Cerrado, entre os períodos de 1990 e 2006. A obtenção desses indicadores - que refletem mudanças nas fontes e diferenças regionais de crescimento da cafeicultura - permitirá compreender melhor os mecanismos de ação das políticas que atuaram no passado e, também, conhecer o setor nas regiões mineiras, auxiliando a formulação de políticas agrícolas regionais.

Este artigo contém cinco seções, incluindo esta introdução. Na seção dois é exposto o referencial teórico que aborda o modelo de inovação induzida, enquanto na seção 3 encontra-se o modelo analítico denominado Shift-Share. Os resultados compõem a seção 4 e, fechando este trabalho, seguem as conclusões.

\section{Referencial teórico}

Para melhor entender as transformações ocorridas nas regiões estudadas, o referencial teórico deste trabalho tomou como base os estudos de Hayami e Ruttan (1988) e de Araújo e Schuh (1975) sobre o modelo de inovação induzida.

Segundo os autores, o modelo de inovação induzida é importante para compreender as direções tomadas pelas mudanças tecnológicas e para demonstrar a dinâmica e as dificuldades do processo de modernização. Ele também apresenta um grande avanço em relação às teorias existentes, pois procura incorporar mudanças na tecnologia e nas instituições como endógenas ao sistema econômico, isto é, orientadas pelas condições de oferta de fatores e de demanda de produtos. ${ }^{6}$ Assim, este modelo torna-se útil para orientar a política de desenvolvimento rural, uma vez que explica o padrão tecnológico seguido por diferentes regiões ao longo do tempo.

Nessa perspectiva, o modelo de inovação induzida supõe que, dadas as alternativas tecnológicas disponíveis, a promoção do desenvolvimento rural irá depender de como tais alternativas serão utilizadas para substituir os fatores de produção escassos - e por isso mais caros - por aqueles relativamente abundantes. Essas alternativas podem ser químico-biológicas, como variedades melhoradas de plantas, fertilizantes e corretivos, assim como tecnológicas, a saber: tratores, semeadeiras e outros equipamentos de natureza mecânica.

Assim, o desenvolvimento de uma região, isto é, a capacidade de se alcançar crescimento rápido na produtividade e produção agrícola, irá depender da capacidade dessa região em realizar uma escolha eficiente entre trajetórias alternativas. Uma escolha equivocada, que não sobrepuja as restrições impostas pela disponibilidade de recursos, pode comprometer todo o processo de desenvolvimento agrícola e econômico. 
Em síntese, pode-se concluir que o modelo de inovação induzida é uma importante ferramenta para explicar algumas diferenças no desenvolvimento rural dos países e regiões produtoras. Esse modelo também serve de base para a criação de mecanismos que apliquem com maior eficiência os recursos, que são escassos, de acordo com as reais prioridades e realidades de cada país e região.

\section{Modelo analítico}

\subsection{O modelo Shift-Share}

Segundo Haddad e Andrade (1989), o modelo Shift-Share procura descrever o crescimento econômico de uma região em termos de sua estrutura produtiva, ou seja, decompor a variação observada na produção entre o período-base "b" e o período final " $\mathrm{f}$ ", a fim de encontrar a diferença $\left(\mathrm{Q}_{\mathrm{f}}-\mathrm{Q}_{\mathrm{b}}\right)$ entre os fatores que seriam os responsáveis pelo crescimento (ou queda) da produção. Desse modo, esse modelo não é uma teoria explicativa do crescimento regional, mas um método de análise para identificar os componentes de crescimento.

Essa metodologia vem sendo utilizada por diversos autores que estudam a agricultura brasileira. Mendes e Fernandes (1976) analisaram o padrão de crescimento de algumas culturas no sul de Minas; Gomes (1990) analisou se os efeitos da modernização são diferentes na região tradicional e na região de expansão de cultivo de soja; Moreira (1996) estudou as principais fontes de crescimento das culturas do Rio Grande do Norte durante o período de 1981 a 1992; e Almeida (2003) desenvolveu um estudo sobre as fontes de crescimento da orizicultura mato-grossense.

Sendo assim, o modelo propõe que a variação da produção de determinada região, em determinado período de tempo, pode ser decomposta em quatro efeitos, denominados efeito área (EA), efeito rendimento (ER), efeito localização geográfica (ELG) e efeito composição (EC).

O efeito área indica que a variação na produção ocorre em virtude da mudança na área cultivada, supondo-se que os demais efeitos permaneçam constantes no tempo. Assim, um aumento na produção é atribuído à incorporação de novas áreas, o que indica o uso extensivo do solo.

O efeito rendimento mensura a variação na produção, explicada exclusivamente pelas mudanças na produtividade. A variação no rendimento pode refletir mudanças tecnológicas, pela adoção de insumos modernos, novas técnicas de produção e maior capacitação do capital humano.

O efeito localização geográfica reflete as mudanças na produção decorrentes das vantagens locacionais, isto é, mantendo-se os demais componentes constantes. Esse efeito mede as mudanças na produção em virtude da localização das culturas entre as regiões estudadas. Segundo Curi (1997), no modelo 
Shift-Share, a localização de uma determinada cultura é vantajosa quando a expansão da área cultivada em alguma região for acompanhada de maiores produtividades e suficiente para contrabalançar a estabilidade ou retração nas demais regiões. No caso de redução generalizada da área cultivada, o efeito ainda será positivo se essa redução ocorrer de forma menos que proporcional nas regiões de maiores ganhos relativos de rendimento.

O efeito composição mostra as variações na produção que são decorrentes das mudanças na estrutura produtiva, isto é, mudanças na proporção da área total utilizada para o plantio da cultura estudada, se mantidos constantes o rendimento e a área total cultivada. A idéia é de que as culturas menos rentáveis sejam substituídas pelas que apresentem maior produtividade por unidade de área.

3.2. Descrição do modelo matemático A descrição do modelo matemático segue os procedimentos adotados por Igreja et al. (1983) e foram adaptados para este trabalho.

3.2.1. Análise em nível estadual

A produção de café no ano inicial "b" pode ser dada pela seguinte expressão:

$$
\mathrm{Q}_{\mathrm{cb}}=\sum_{\mathrm{m}=1}^{\mathrm{j}} \alpha_{\mathrm{cmb}} \mathrm{A}_{\mathrm{cb}} \mathrm{R}_{\mathrm{cmb}}
$$

Em que:

$$
\begin{aligned}
\mathrm{Q}_{\mathrm{cb}}= & \begin{array}{l}
\text { quantidade de café produzido no estado de Minas Gerais no } \\
\text { período-base }(\mathrm{b}) ;
\end{array} \\
\mathrm{a}_{\mathrm{cmb}}= & \begin{array}{l}
\text { razão entre a área cultivada de café na m-ésima região e a área } \\
\text { total cultivada de café no Estado ( } \left.\mathrm{AT}_{\mathrm{cmt}} / \mathrm{AT}_{\mathrm{ct}}\right) \text {, no período- } \\
\\
\text { base; }
\end{array} \\
\mathrm{A}_{\mathrm{cb}}= & \begin{array}{l}
\text { área total de café cultivada no estado, no período-base, em } \\
\text { hectares; e }
\end{array} \\
\mathrm{R}_{\mathrm{cmb}}= & \begin{array}{l}
\text { rendimento por hectare de café na m-ésima região do estado, } \\
\text { no período-base. }
\end{array}
\end{aligned}
$$

Na determinação dos componentes responsáveis pelo crescimento (redução) da produção de café em Minas Gerais $\left(\mathrm{Q}_{\mathrm{cf}}-\mathrm{Q}_{\mathrm{cb}}\right)$, são definidas duas novas equações a partir da equação (1).

A primeira delas é a equação (2), que difere da primeira apenas pela substituição de $\mathrm{A}_{\mathrm{cb}}$ por $\mathrm{A}_{\mathrm{cf}}$, que é a área cultivada de café no período final "f".

$$
\mathrm{Q}_{\mathrm{cf}}^{*}=\sum_{\mathrm{m}=1}^{\mathrm{j}} \alpha_{\mathrm{cmb}} \mathrm{A}_{\mathrm{cf}} \mathrm{R}_{\mathrm{cmb}}
$$


Sendo que:

$\mathrm{Q}_{\mathrm{cf*}}=$ quantidade de café produzido no estado de Minas Gerais no período final (f), considerando que tudo o mais permaneça constante e apenas há variação na área cultivada;

$\alpha_{\mathrm{cmb}}=$ razão entre a área cultivada de café na m-ésima região e a área total cultivada de café no estado $\left(\mathrm{AT}_{\mathrm{cmt}} / \mathrm{AT}_{\mathrm{ct}}\right)$, no períodobase;

$\mathrm{A}_{\mathrm{cf}}=$ área total de café cultivada no estado, no período final, em hectares; e

$\mathrm{R}_{\mathrm{cmb}}=$ rendimento por hectare de café na m-ésima região do estado, no período-base.

Logo, segue-se equivalentemente que a diferença $\left(Q_{c f}{ }^{*}-Q_{c b}\right)$ representa a parcela de crescimento (redução) da produção, que pode ser atribuída ao aumento (redução) da área cultivada.

A segunda equação definida a partir de (1) é a equação (3). Nesta, tanto a área $\mathrm{A}_{\mathrm{cf}}$ quanto o rendimento $\mathrm{R}_{\mathrm{cmf}}$ são definidos para o período final "f".

$$
\mathrm{Q}_{\mathrm{cf}}^{* *}=\sum_{\mathrm{m}=1}^{\mathrm{j}} \alpha_{\mathrm{cmb}} \mathrm{A}_{\mathrm{cf}} \mathrm{R}_{\mathrm{cmf}}
$$

Em que:

$\mathrm{Q}_{\mathrm{cf}^{* *}}=$ quantidade de café produzido no estado de Minas Gerais no período final (f), quando área e rendimento variam;

$a_{\mathrm{cmb}}=$ razão entre a área cultivada de café na m-ésima região e a área total cultivada de café no estado $\left(\mathrm{AT}_{\mathrm{cmt}} / \mathrm{AT}_{\mathrm{ct}}\right)$, no períodobase;

$\mathrm{A}_{\mathrm{cf}}=$ área total de café cultivada no estado, no período final, em hectares; e

$\mathrm{R}_{\mathrm{cmf}}=$ rendimento por hectare de café na m-ésima região do estado, no período-final.

Por último, variando área, rendimento e localização geográfica, a produção no período final é definida por:

$$
\mathrm{Q}_{\mathrm{cf}}=\sum_{\mathrm{m}=1}^{\mathrm{j}} \alpha_{\mathrm{cmf}} \mathrm{A}_{\mathrm{cf}} \mathrm{R}_{\mathrm{cmf}}
$$


Sendo que:

$\mathrm{Q}_{\mathrm{cf}}=$ quantidade de café produzido no estado de Minas Gerais no período final (f);

$\alpha_{\text {cmf }}=$ razão entre a área cultivada de café na m-ésima região e a área total cultivada de café no estado $\left(\mathrm{AT}_{\mathrm{cmt}} / \mathrm{AT}_{\mathrm{ct}}\right)$, no período final;

$\mathrm{A}_{\mathrm{cf}}=$ área total de café cultivada no estado, no período final, em hectares; e

$\mathrm{R}_{\mathrm{cmf}}=$ rendimento por hectare de café na m-ésima região do estado, no período final.

Em síntese, tem-se que:

$$
\begin{aligned}
& \left(\mathrm{Q}_{\mathrm{cf}} *-\mathrm{Q}_{\mathrm{cb}}\right)=\text { variação total na quantidade produzida entre os período } \\
& \text { "b" e "f" quando somente a área se altera, ou seja, efeito } \\
& \text { área (EA); } \\
& \left(Q_{c f}^{* *}-Q_{c f}^{*}\right)=\text { variação total na quantidade produzida entre os períodos } \\
& \text { "b" e "f" quando somente o rendimento se altera, ou seja, } \\
& \text { efeito rendimento (ER); e } \\
& \left(\mathrm{Q}_{\mathrm{cf}}-\mathrm{Q}_{\mathrm{cf}}{ }^{* *}\right)=\text { variação total na quantidade produzida entre os períodos } \\
& \text { "b" e "f" quando somente a localização geográfica se } \\
& \text { altera, ou seja, efeito localização geográfica (EG). }
\end{aligned}
$$

Os resultados também podem ser apresentados na forma de taxas anuais de crescimento, sendo, portanto, expressos individualmente como uma percentagem da mudança total na produção.

O ponto de partida é encontrar os membros que representam a diferença no volume de produção obtida entre o período inicial "b" e o período final "f":

$$
\left(Q_{c f}-Q_{c b}\right)=\left(Q_{c f}^{*}-Q_{c b}\right)+\left(Q_{c f}^{* *}-Q_{c f}^{*}\right)+\left(Q_{c f}-Q_{c f}^{* *}\right)
$$

Em seguida, divide-se toda a expressão (5) por $\left(\mathrm{Q}_{\mathrm{cf}}-\mathrm{Q}_{\mathrm{cb}}\right)$, multiplicando por:

$$
r=\left(\sqrt[f]{\frac{\mathrm{Q}_{\mathrm{cf}}}{\mathrm{Q}_{\mathrm{cb}}}}-1\right) 100
$$

Em que $r$ é a taxa anual média de variação na produção, em porcentagem, obtendo-se, dessa forma, a seguinte expressão:

$$
r=\frac{\left(Q_{c f}^{*}-Q_{c b}\right)}{\left(Q_{f f}-Q_{c b}\right)}\left(Q_{c f}^{* *}-Q_{c f}^{*}\right) r+\left(Q_{c f}-Q_{c f}^{* *}\right) r
$$


O primeiro termo à direita da expressão (7) representa o efeito área; o termo seguinte, o efeito rendimento; e o último termo, o efeito localização geográfica todos expressos em taxa de crescimento ao ano, em percentagem.

3.2.2. Análise em nível regional Quando se estudam as regiões do estado, o efeito localização geográfica se torna nulo. Desse modo, no estudo do crescimento da produção de café utilizamse apenas os efeitos área e rendimento e inclui-se o efeito composição.

Em uma determinada série temporal, a produção de café "c" na m-ésima região, no ano inicial "b", pode ser dada pela seguinte expressão:

$$
\mathrm{P}_{\mathrm{cmb}}=\sum_{\mathrm{m}=1}^{\mathrm{j}} \beta_{\mathrm{cmb}} \mathrm{A}_{\mathrm{mb}} \mathrm{R}_{\mathrm{cmb}}
$$

Em que:

$$
\begin{aligned}
\mathrm{P}_{\mathrm{cmb}}= & \begin{array}{l}
\text { quantidade de café produzido na m-ésima região do estado no } \\
\text { período-base }(\mathrm{b}) ;
\end{array} \\
\beta_{\mathrm{cmb}}= & \begin{array}{l}
\text { razão entre a área cultivada de café na m-ésima região e a área total } \\
\text { cultivada na m-ésima região do estado }\left(\mathrm{AT}_{\mathrm{cmt}} / \mathrm{AT}_{\mathrm{mt}}\right) \text {, no período- } \\
\text { base; }
\end{array} \\
\mathrm{A}_{\mathrm{mb}}= & \begin{array}{l}
\text { área total das culturas (dimensão do sistema de produção) cultivada } \\
\text { na m-ésima região do estado, no período-base, em hectares; e }
\end{array} \\
\mathrm{R}_{\mathrm{cmb}}= & \begin{array}{l}
\text { rendimento por hectare de café na m-ésima região do estado, no } \\
\text { período-base. }
\end{array}
\end{aligned}
$$
$\mathrm{A}_{\mathrm{mb}}=$ área total das culturas (dimensão do sistema de produção) cultivada na m-ésima região do estado, no período-base, em hectares; e

Para determinar os responsáveis pelo crescimento (redução) da produção de café na região " $\mathrm{m}$ " $\left(\mathrm{P}_{\mathrm{cmf}}-\mathrm{P}_{\mathrm{cmb}}\right)$, são definidas duas novas equações a partir da equação (8).

A primeira delas é a equação (9), que difere da equação (10) apenas pela substituição de $\mathrm{A}_{\mathrm{mb}}$ por $\mathrm{A}_{\mathrm{mf}}$, que é a área cultivada de café no período final "f".

$$
\mathrm{P}_{\mathrm{cmf}}{ }^{*}=\sum_{\mathrm{m}=1}^{\mathrm{j}} \beta_{\mathrm{cmb}} \mathrm{A}_{\mathrm{mf}} \mathrm{R}_{\mathrm{cmb}}
$$

Em que:

$\mathrm{P}_{\mathrm{cmf}}{ }^{*}=$ quantidade de café produzido na m-ésima região do estado se tudo o mais permanecesse constante e há apenas a variação na área cultivada;

$\beta_{\mathrm{cmb}}=$ razão entre a área cultivada de café na m-ésima região e a área total cultivada na m-ésima região do estado $\left(\mathrm{AT}_{\mathrm{cmt}} / \mathrm{AT}_{\mathrm{mt}}\right)$, no período-base; 


$$
\begin{aligned}
\mathrm{A}_{\mathrm{mf}}= & \begin{array}{l}
\text { área total das culturas (dimensão do sistema de produção) } \\
\text { cultivada na m-ésima região do estado, no período final (f), em }
\end{array} \\
& \text { hectares; e } \\
\mathrm{R}_{\mathrm{cmb}}= & \begin{array}{l}
\text { rendimento por hectare de café na m-ésima região do estado, } \\
\text { no período-base. }
\end{array}
\end{aligned}
$$

Segue-se, equivalentemente, que a diferença $\left(\mathrm{P}_{\mathrm{cmf}}{ }^{*}-\mathrm{P}_{\mathrm{cmb}}\right)$ representa a parcela de crescimento (redução) da produção, que pode ser atribuída ao aumento (redução) da área cultivada.

A próxima equação definida a partir de (8) é a equação (10). Nesta, tanto a área $\mathrm{A}_{\mathrm{mf}}$ quanto o rendimento $\mathrm{R}_{\mathrm{cmf}}$ estão no período final "f".

$$
\mathrm{P}_{\mathrm{cmf}}^{* * *}=\sum_{\mathrm{m}=1}^{\mathrm{j}} \beta_{\mathrm{cmb}} \mathrm{A}_{\mathrm{mf}} \mathrm{R}_{\mathrm{cmf}}
$$

Sendo que:

$$
\begin{aligned}
& \mathrm{P}_{\mathrm{cmf}}{ }^{* *}=\begin{array}{l}
\text { quantidade de café produzido na m-ésima região do estado } \\
\text { no período final; }
\end{array} \\
& \left.\beta_{\mathrm{cmb}}=\quad \begin{array}{l}
\text { razão entre a área cultivada de café na m-ésima região e a } \\
\text { área total cultivada na m-ésima região do estado (AT } \mathrm{Amt}_{\mathrm{cm}} / \\
\mathrm{AT}
\end{array}\right) \text {, no período-base; } \\
& \mathrm{A}_{\mathrm{mf}}=\quad \begin{array}{l}
\text { área total das culturas (dimensão do sistema de produção) } \\
\text { cultivadas na m-ésima região do estado, no período final, em } \\
\text { hectares; }
\end{array} \\
& \mathrm{R}_{\mathrm{cmf}}=\quad \begin{array}{l}
\text { rendimento por hectare de café na m-ésima região do estado, } \\
\text { no período final. }
\end{array}
\end{aligned}
$$

Por último, variando a área, o rendimento e a composição, a produção no período final é dada por:

$$
\mathrm{P}_{\mathrm{cmf}}=\sum_{\mathrm{m}=1}^{\mathrm{j}} \beta_{\mathrm{cmf}} \mathrm{A}_{\mathrm{mf}} \mathrm{R}_{\mathrm{cmf}}
$$

Em que:

$\mathrm{P}_{\mathrm{cmf}}=$ quantidade de café produzido na m-ésima região do estado no período final;

$\beta_{\mathrm{cmf}}=$ razão entre a área cultivada de café na m-ésima região e a área total cultivada na m-ésima região do estado $\left(\mathrm{AT}_{\mathrm{cmt}} / \mathrm{AT}_{\mathrm{mt}}\right)$, no período final;

$\mathrm{A}_{\mathrm{mf}}=$ área total das culturas (dimensão do sistema de produção) cultivadas na m-ésima região do estado, no período final, em hectares; e 


$$
\begin{aligned}
\mathrm{R}_{\mathrm{cmf}}= & \text { rendimento por hectare de café na m-ésima região do estado, } \\
& \text { no período final. }
\end{aligned}
$$

Em síntese, tem-se que:

$$
\begin{aligned}
& \left(\mathrm{P}_{\mathrm{cmf}}{ }^{*}-\mathrm{P}_{\mathrm{cmb}}\right)=\text { efeito área (EA); } \\
& \left(\mathrm{P}_{\mathrm{cmf}}{ }^{* *}-\mathrm{P}_{\mathrm{cmf}}{ }^{*}\right)=\text { efeito rendimento (ER); e } \\
& \left(\mathrm{P}_{\mathrm{cmf}}-\mathrm{P}_{\mathrm{cmf}}{ }^{* *}\right)=\text { efeito composição (EC). }
\end{aligned}
$$

O processo utilizado para transformar os efeitos obtidos anteriormente em taxas anuais de crescimento é semelhante ao empregado no item anterior.

\subsection{Decomposição do efeito área nos efeitos escala e substituição}

Para analisar as mudanças na composição agrícola, utiliza-se o modelo desenvolvido por Zockum (1978) e utilizado por Gomes (1990) e Santos et al. (2000), o qual pressupõe que a área cultivada com determinada cultura num determinado período, dentro do sistema de produção, pode ser alterada devido aos efeitos escala e substituição.

O efeito escala consiste no resultado da variação da área cultivada com determinada atividade, entre dois períodos de tempo, mantida a sua participação relativa no sistema.

O efeito substituição mostra a variação da participação de cada cultura dentro do sistema. Esse efeito pode ser negativo, ou seja, quando no período analisado a cultura estudada foi substituída por outra(s) cultura(s) do sistema (queda da partição), ou positivo, quando no período analisado a participação do produto eleva-se, indicando que a cultura considerada substituiu outra(s) cultura(s) dentro do sistema (aumento da participação).

Assim, a variação na área ocupada pelo café, em cada sistema de produção (ou m-ésima região), pode ser assim definida:

$$
\left(\mathrm{A}_{\mathrm{cmf}}-\mathrm{A}_{\mathrm{cmb}}\right)
$$

Em que:

$\mathrm{A}_{\mathrm{cmb}}=$ área total de café cultivada na m-ésima região, no período base (b), em hectares; e

$\mathrm{A}_{\mathrm{cmf}}=$ área total de café cultivada na m-ésima região, no período final (f), em hectares.

O que pode ser decomposto nos efeitos escala e substituição, medidos em hectares:

$$
\begin{aligned}
& \left(\lambda \mathrm{A}_{\mathrm{cmb}}-\mathrm{A}_{\mathrm{cmb}}\right)=\text { efeito escala (EE) } \\
& \left(\mathrm{A}_{\mathrm{cmf}}-\lambda \mathrm{A}_{\mathrm{cmb}}\right)=\text { efeito substituição (ES) }
\end{aligned}
$$


Ou seja:

$$
\left(\mathrm{A}_{\mathrm{cmf}}-\mathrm{A}_{\mathrm{cmb}}\right)=\left(\lambda \mathrm{A}_{\mathrm{cmb}}-\mathrm{A}_{\mathrm{cmb}}\right)+\left(\mathrm{A}_{\mathrm{cmf}}-\lambda \mathrm{A}_{\mathrm{cmb}}\right)
$$

Sendo $\lambda$ o coeficiente que mede a modificação na área total cultivada de café entre os períodos "b" (inicial) e "f" (final), ( $\left.\mathrm{AT}_{\mathrm{f}} / \mathrm{AT}_{\mathrm{b}}\right)$.

Assim, os efeitos escala e substituição são obtidos da decomposição da variação da área cultivada com café dentro do sistema (ou da m-ésima região).

Finalmente, estabelecidas as fontes de crescimento da cafeicultura em Minas Gerais e nas regiões Sudoeste e Cerrado desse estado, a tarefa seguinte foi explicar por que existem diferenças entre as regiões e ao longo do período analisado no que diz respeito às fontes que determinam o crescimento do referido produto. Para isso, foram utilizados dados do Instituto Brasileiro de Geografia e Estatística (IBGE) e da Companhia Nacional de Abastecimento (CONAB). O período de análise compreendeu os anos de 1990 a 2006 e a série de dados representa as médias anuais para cada uma das variáveis.

\section{Resultados}

\subsection{Decomposição da variação da produção de café em Minas Gerais}

Neste tópico, busca-se explicar o comportamento da produção de café em Minas Gerais por meio da decomposição desta nos efeitos área, rendimento e localização geográfica. Para os resultados concernentes às fontes de crescimento da cafeicultura mineira, são adotados dois tipos de quantificação: a primeira refere-se a uma análise que abrangeu o período estudado por completo (1990 a 2006), e a segunda considerou o mesmo período dividido em cinco subperíodos: 1990-1995, 1993-1998, 1996-2001, 1999-2004 e 2002-2006. Ambas as análises encontram-se na Tabela 1.

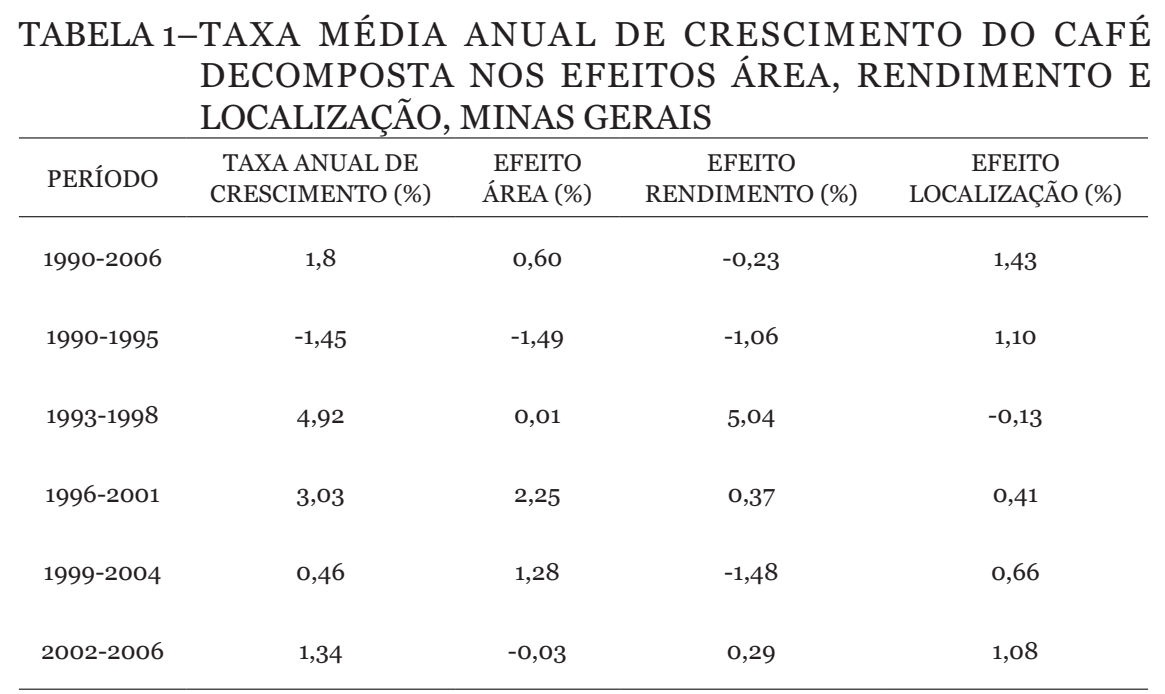

FONTE: Dados básicos do IBGE e CONAB (2006) 
De acordo com esses dados, no período de 1990 a 2006 a produção de café no estado apresentou taxa anual de crescimento de 1,8\%. O efeito localização foi determinante para esse resultado, ao apresentar taxa anual de crescimento de 1,43\%; enquanto isso, o efeito rendimento apresentou taxa de crescimento negativa de $0,23 \%$, não favorecendo o crescimento da produção durante o período relacionado. Em contrapartida, o efeito área contribuiu para o desempenho positivo da produção de café no estado, sendo este igual a o,60\% a.a. Assim, as incorporações de novas áreas agrícolas e as substituições de culturas menos eficientes representaram os mais importantes mecanismos de crescimento da produção de café em Minas Gerais durante o período selecionado.

Ao estudar as fontes de crescimento da agricultura mineira durante o período de 1980 a 1996, Curi (1997) observou que o café, a soja e a cana-de-açúcar foram as culturas que mostraram as maiores taxas de crescimento da produção. O efeito área foi o principal responsável por tal resultado, uma vez que os efeitos rendimento e localização geográfica foram negativos para as três culturas. Curi (1997) também constatou que o crescimento da produção agrícola convergiu para as macrorregiões que, anteriormente, receberam os maiores benefícios da ação de programas e projetos, levados a efeito pelo estado.

Já Alves e Shikida (2001), ao realizarem o mesmo estudo para as principais culturas da agricultura paranaense entre 1981 e 1989, constataram que, dos fatores explicativos, o maior responsável pelo crescimento da agricultura no estado foi o efeito rendimento. Dessa forma, o crescimento da produção agrícola no Paraná não ocorreu via incorporação de novas áreas, mas através da modernização do setor, decorrente da influência das políticas nacionais no estado.

Considerando os subperíodos estudados, observa-se que todos, exceto 1990-1995, apresentaram taxa anual de crescimento positiva. O destaque foi o subperíodo 1993-1998 com crescimento da produção de 4,92\% a.a. e importante participação do efeito rendimento (5,04\%). Já o efeito área foi praticamente nulo (o,01\% a.a.) e o efeito localização foi negativo, porém, pequeno (-o,13\% a.a.).

Dessa forma, pode-se afirmar que as variações na produção de café entre os anos 1993 e 1998 não tiveram forte ligação com o incremento de área, tampouco com as vantagens locacionais dessa cultura entre as regiões consideradas neste trabalho (Sudoeste e Cerrado). O certo é que quase todo o incremento na produção foi decorrente da variação positiva da produtividade, ou seja, essa variação positiva da produção pode estar refletindo mudanças tecnológicas devido à adoção de novos insumos, novas técnicas de produção e melhoria do capital humano.

Durante o período 1996-2001, observa-se taxa média de crescimento na ordem de $3,03 \%$ ao ano, com importante participação do efeito área (2,25\% a.a.) e participações positivas do efeito rendimento (o,37\% a.a.) e do efeito localização (o,41\% a.a.). Desse modo, o efeito área foi o mais relevante para explicar o bom desempenho da atividade cafeeira no período, ou seja, a produção de café em Minas Gerais expandiuse através da substituição de outras culturas menos rentáveis e pela exploração de novas áreas que não estavam sendo utilizadas em atividades agrícolas. 
Os resultados dos subperíodos 1993-1998 e 1996-2001 podem ser reflexos dos bons preços praticados a partir de 1994 (Figura 1). Esse fato estimulou os produtores a abrirem novas áreas de cultivo e a aumentarem os tratos culturais naquelas áreas que já estavam sendo utilizadas. Dessa forma, verificou-se aumento da produção através do incremento da produtividade (entre 1993 e 1998) e, posteriormente, via aumento da área (entre 1996 e 2001), como exposto anteriormente. ${ }^{7}$

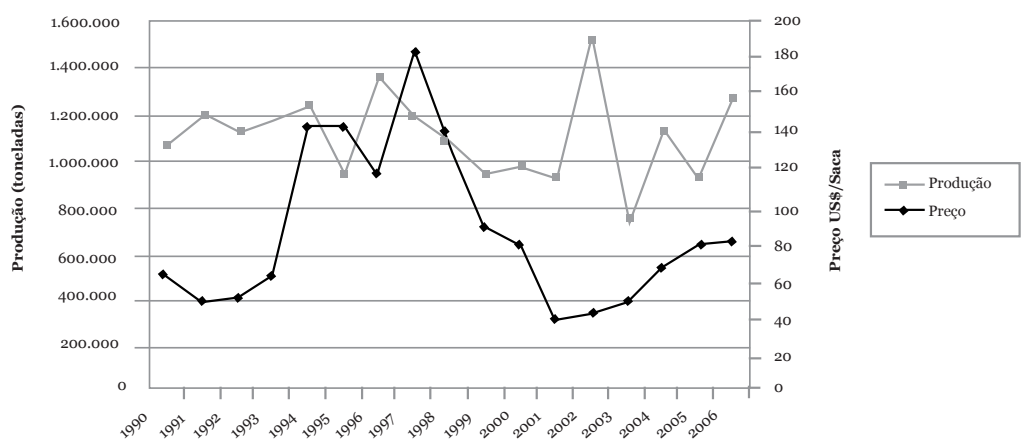

FONTE: Dados básicos do IBGE, CONAB (2006) e CIC (2007)

\section{FIGURA 1-PRODUÇÃO DE CAFÉ (TONELADAS) EM MINAS GERAIS E PREÇOS MÉDIOS, DO CAFÉ ARÁBICA PAGO AO PRODUTOR NO BRASIL - 1990-2006}

Entre 1990 e 1995, a produção de café no estado apresentou queda de 1,45\% ao ano. O maior responsável por esse resultado foi o efeito área (-1,49\% a.a.), seguido do efeito rendimento (-1,06\% a.a.). Ao contrário, o efeito localização foi positivo e igual a $1,10 \%$ ao ano, revelando que, apesar da queda na produção, a localização das culturas, entre as regiões estudadas, favoreceu a atividade cafeeira em Minas Gerais. No entanto, esse efeito positivo não foi suficiente para contrapor os efeitos negativos de área e rendimento.

Fazendo novamente alusão à Tabela 1, que mostra as fontes de crescimento da produção de café em Minas Gerais, e à Figura 1, que se refere aos preços médios do café arábica pagos ao produtor, observa-se que os efeitos área e produtividade respondem de forma diferente aos estímulos do mercado, principalmente aos estímulos dos preços.

O rendimento tende a demonstrar resposta mais imediata para os estímulos dos preços, ou seja, nos períodos em que os preços do café estão em baixa, observa-se que o efeito rendimento é nulo ou negativo; ao contrário, quando os preços estão em ascensão, o efeito rendimento é positivo e significativo para explicar o crescimento da produção de café no estado. Quanto à área colhida, as respostas são no mesmo sentido que as do rendimento, porém estas acontecem com certa defasagem. A idéia é de que os produtores, ao verem os bons preços pagos pelo café no mercado, sentem-se estimulados a aumentar a sua área de plantio, porém, em virtude da própria natureza dessa planta, 
sua colheita só poderá ser realizada três anos após o plantio. Dessa forma, os preços pagos ao produtor provavelmente não serão mais os mesmos, uma vez que surge no mercado expectativa de aumento da oferta de café.

Diante disso, é importante identificar como a expansão da cafeicultura em Minas Gerais afetou a composição agrícola e como se comportaram as principais culturas do estado. Essa análise pode ser realizada ao observar os efeitos escala e substituição no sistema de produção considerado (Minas Gerais), que se encontram na Tabela 2.

\section{TABELA 2 - PARTICIPAÇÃO, EM ÁREA, DAS PRINCIPAIS CULTURAS MINEIRAS DECOMPOSTAS NOS EFEITOS ESCALA E SUBSTITUIÇÃO (HECTARES), NA MUDANÇA DO SISTEMA DE PRODUÇÃO - 1990-2006}

\begin{tabular}{|c|c|c|c|}
\hline \multicolumn{4}{|c|}{ EFEITOS (HA.) } \\
\hline CULTURAS & TOTAL & SUBSTITUIÇÃO & ESCALA \\
\hline \multicolumn{4}{|c|}{ EFEITO ÁREA POSITIVO } \\
\hline Café & $124.155,33$ & $146.125,00$ & $-21.969,67$ \\
\hline Soja & $396.314,30$ & $407.826,00$ & $-11.511,64$ \\
\hline Cana-de-açúcar & $23.111,67$ & $29.604,00$ & $-6.492,44$ \\
\hline Outras & $107.272,30$ & $112.240,00$ & $-4.967,62$ \\
\hline Subtotal & $650.853,70$ & $695.795,00$ & $-44 \cdot 941,35$ \\
\hline \multicolumn{4}{|c|}{ EFEITO ÁREA NEGATIVO } \\
\hline Algodão & $-78.455,00$ & $-75.696,00$ & $-2.759,00$ \\
\hline Arroz & $-336.158,00$ & $-326.276,33$ & $-9.881,67$ \\
\hline Feijão & $-106.758,00$ & $-94.461,95$ & $-12.296,05$ \\
\hline Milho & $-233 \cdot 759,33$ & $-199.360,74$ & $-34 \cdot 398,60$ \\
\hline Subtotal & $-755 \cdot 130,30$ & $-695 \cdot 795,00$ & $-59 \cdot 335,30$ \\
\hline TOTAL & $-104.276,70$ & 0,00 & $-104.276,70$ \\
\hline
\end{tabular}

FONTE: Dados básicos do IBGE e CONAB (2006)

No período de 1990 a 2006, o estado de Minas Gerais obteve retração equi valente a 104.276,70 hectares de área ocupada; isso significa um efeito escala negativo, ou seja, houve retração absoluta das áreas das culturas, que podem ter sido ocupadas por pastagens e reflorestamento ou ainda ficado em pousio. 
As culturas que apresentaram efeito área positivo (650.853,70 ha) foram o café, a soja e a cana-de-açúcar; elas também tiveram efeito substituição positivo, com destaque para a soja, que absorveu $58 \%$ de toda a área cedida dentro do sistema. Também pode ser observado na Tabela 2 que todas as culturas apresentaram efeito escala negativo, isto é, nenhuma cultura incorporou novas áreas que antes não estavam sendo utilizadas para cultivo. Assim, o efeito área positivo encontrado para a cafeicultura em Minas Gerais durante o período estudado (Tabela 1) pode ser completamente atribuído ao efeito substituição, que foi suficiente para compensar o efeito escala negativo.

A área cultivada do café expandiu-se em 124.155,33 hectares, sendo responsável, por 21\% das substituições do sistema, isto é, durante o período analisado foram cedidos 146.125 hectares de área para o café; no entanto, o efeito escala foi negativo $(-21.969,67$ ha), o que indica que houve retração do café dentro do sistema em termos de escala.

Dos 695.795 hectares de área cedidos no sistema, o arroz foi o maior responsável, cedendo o equivalente a 46,9\% do total. Em seguida, tem-se o milho (28,65\%), o feijão $(13,58 \%)$ e, por último, o algodão $(10,9 \%)$.

Em suma, entre as culturas que apresentaram efeito área positivo estão aquelas cultivadas por grandes produtores e/ou voltadas para o mercado internacional, como a cana-de-açúcar, a soja e o café. Já aquelas que apresentaram efeito área negativo englobam, principalmente, as culturas tradicionais de subsistência como o arroz, o feijão e o milho.

\subsection{Decomposição da variação da produção de café nas regi- ões Cerrado e Sudoeste de Minas Gerais}

O estudo da cafeicultura nas regiões mineiras (Cerrado e Sudoeste) é realizado com base na quantidade produzida de café em cada uma dessas regiões. Nesse caso, são mensurados os efeitos área, rendimento e composição, já que o efeito localização torna-se nulo na análise de crescimento da cultura relacionada para cada uma das regiões.

A Tabela 3 fornece as fontes de crescimento da produção de café no Cerrado Mineiro entre 1990 e 2006 e entre os subperíodos 1990-1995, 1993-1998, 1996-2001, 1999-2004 e 2002-2006.

Os resultados, para o período por completo, indicam que houve crescimento positivo da produção na ordem de $0,38 \%$ ao ano. Esse crescimento teve como principais fatores os efeitos área (1,90\% a.a.) e rendimento (o,38\% a.a.) e, como contrafator, o efeito composição (-1,90\% a.a.). É importante ressaltar que nesse período o efeito composição negativo foi completamente compensado pelo efeito área positivo; dessa forma, o crescimento da produção equivaleu-se ao desempenho positivo da produtividade.

Assim, evidencia-se que no Cerrado de Minas os fatores responsáveis pelo crescimento da produção entre 1990 e 2006 foram o acréscimo da área colhida e da produtividade, que, somados, compensaram os efeitos negativos causados na produção em decorrência da mudança na estrutura produtiva da região. 
TABELA 3 - TAXA MÉDIA ANUAL DE CRESCIMENTO DO CAFÉ DECOMPOSTA NOS EFEITOS ÁREA, RENDIMENTO E COMPOSIÇÃO, CERRADO DE MINAS

\begin{tabular}{ccccc}
\hline \multirow{2}{*}{ PERÍODO } & $\begin{array}{c}\text { TAXA ANUAL DE } \\
\text { CRESCIMENTO (\%) }\end{array}$ & $\begin{array}{c}\text { EFEITO } \\
\text { AREA (\%) }\end{array}$ & $\begin{array}{c}\text { EFEITO } \\
\text { RENDIMENTO (\%) }\end{array}$ & $\begin{array}{c}\text { EFEITO } \\
\text { COMPOSIÇÃO (\%) }\end{array}$ \\
\hline $1990-2006$ & 0,38 & 1,90 & 0,38 & $-1,90$ \\
$1990-1995$ & $-1,12$ & 0,99 & 1,32 & $-3,43$ \\
$1993-1998$ & 4,3 & $-4,34$ & 7,50 & 1,14 \\
$1996-2001$ & 7,95 & 1,29 & 3,21 & 3,45 \\
$1999-2004$ & $-6,34$ & 5,42 & $-8,91$ & $-2,85$ \\
$2002-2006$ & $-0,94$ & 0,72 & $-0,06$ & $-1,60$ \\
\hline
\end{tabular}

FONTE: Dados básicos do IBGE e CONAB (2006)

A análise realizada entre os subperíodos evidencia que entre 1996 e 2001 a taxa anual de crescimento apresentou seu maior índice em comparação aos demais períodos (7,95\%). Nesse período também se constatou que tanto os efeitos área como os efeitos rendimento e composição foram positivos: 1,29\% a.a., 3,21\% a.a. e 3,45\% a.a., respectivamente.

O efeito composição foi o que apresentou maior peso para o bom resultado proporcionado pela produção de café na região durante o subperíodo supracitado. Isso significa que, se o rendimento e a área total cultivada com o café na região forem mantidos constantes, haverá expansão da produção de $3,45 \%$ a.a., em virtude da melhor produtividade do café e da expansão deste em detrimento de outras culturas menos rentáveis.

Já entre 1999 e 2004 a produção apresentou queda de 6,34\% ao ano. Embora o efeito área tenha se mostrado importante nesse subperíodo (5,42\% a.a.), ele não foi suficiente para anular o desempenho negativo dos efeitos composição $(-2,85 \%$ a.a.) e rendimento $(-8,91 \%$ a.a. $)$, que foram determinantes para 0 péssimo desempenho da produção no subperíodo.

Mais uma vez, as oscilações do efeito rendimento em todos os períodos podem ser atribuídas às variações no preço do café, isto é, quando o preço dessa commodity está alto, a tendência é de que os produtores se sintam incentivados a melhorar os tratos culturais e a adotar algum tipo de tecnologia que aumente a produtividade, sendo o contrário também verdadeiro.

Para o Cerrado, que apresenta os melhores índices de produtividade do estado, o efeito rendimento foi positivo em períodos nos quais os preços se apresentavam crescentes (1993-1998) e negativo quando eles foram decrescentes (1999-2004), como mostrado na Figura 1.

Outra forma de examinar o efeito área é decompondo-o nos efeitos escala e rendimento, ou seja, verificar se houve aumento ou redução do sistema de 
produção (efeito escala) e se a área de café substituiu ou foi substituída pelas demais culturas da região (efeito substituição). Esses resultados podem ser observados na Tabela 4.

\begin{tabular}{|c|c|c|c|}
\hline \multirow[b]{2}{*}{ PERÍODO } & \multirow[b]{2}{*}{ TOTAL } & EFEITO ÁREA & \multirow[b]{2}{*}{ SUBSTITUIÇÃO } \\
\hline & & ESCALA & \\
\hline 1990-2006 & 2.388 & $52.846,96$ & $-50.458,96$ \\
\hline 1990-1995 & -19.928 & $8.951,43$ & $-28.879,43$ \\
\hline 1993-1998 & -13.899 & $-17.560,70$ & $3.661,70$ \\
\hline 1996-2001 & 36.671 & $11.437,84$ & $25.223,16$ \\
\hline 1999-2004 & 7.997 & $43.835,57$ & $-35.838,57$ \\
\hline 2002-2006 & -8.453 & $47.560,04$ & $-56.013,04$ \\
\hline
\end{tabular}

FONTE: Dados básicos do IBGE e CONAB (2006)

Se analisados os anos de 1990 a 2006, os resultados (Tabela 4) indicarão que o efeito escala foi responsável pela incorporação de 52.846,96 hectares de café no Cerrado de Minas, ao passo que, através do efeito substituição, foram cedidos 50.458,96 hectares da área de café a outras culturas, ou seja, o efeito área - variação na produção em virtude da variação da área supondo-se que o rendimento e a estrutura de cultivo permaneçam constantes - teve influência positiva e igual a 2.388 hectares na produção de café.

Desse modo, poderia se entender que o aumento da área plantada seria um caminho natural para o incremento das safras de café na região. Entretanto, é bastante improvável que isso ocorra no curto prazo, já que, com a valorização do álcool, a produção de cana-de-açúcar tem crescido de forma acelerada, principalmente nessa região. A idéia é que as áreas de pastagens que poderiam receber cafezais, atualmente, estão sendo ocupadas pela cana-de-açúcar.

Passando para o subperíodo 1990-1995, observa-se que a produção de café teve efeito escala positivo igual a 8.951,43 hectares, o que significa que houve aumento absoluto da área de café. Esse fato pode ser creditado à ocupação de áreas que antes não estavam sendo utilizadas em atividades agrícolas, como pastagens nativas e reflorestamento, ou simplesmente ficando em pousio. Isso também ocorreu no subperíodo 1996-2001 e, com mais intensidade, em 1999-2004 e 2002-2006, conforme indicado na Tabela 4. 
Nos subperíodos 1990-1995, 1999-2004 e 2002-2006, a produção de café do Cerrado de Minas apresentou efeito substituição negativo, cedendo um total de -28.879,43, -35.838,57 e -56.013,04 hectares de área, respectivamente. Já no terceiro e no quarto subperíodos (1993-1998 e 1996-2001), as demais culturas existentes no Cerrado cederam à cafeicultura o equivalente a $28.884,84$ hectares.

Os fatores que determinaram o crescimento (queda) da produção de café na região Sudoeste de Minas Gerais podem ser visualizados na Tabela 5. Nela é possível observar como se comportaram as fontes de crescimento da cafeicultura na região entre 1990 e 2006.

\begin{tabular}{ccccc} 
TABELA $5-$ & \multicolumn{5}{l}{ TAXA MÉDIA ANUAL DE CRESCIMENTO DO CAFÉ } \\
& \multicolumn{4}{c}{ DECOMPOSTA } \\
& COMPOSIÇÃO & - SUDOESTE DE MINAS & \\
\hline PERÍODO & TAXA ANUAL DE & EFEITO & EFEITO & EFEITO \\
& CRESCIMENTO (\%) & ÁREA (\%) & RENDIMENTO (\%) & COMPOSIÇÃO (\%) \\
\hline $1990-2006$ & 2,59 & 0,36 & $-0,50$ & 2,73 \\
$1990-1995$ & $-1,81$ & $-0,74$ & 1,07 & $-2,14$ \\
$1993-1998$ & 6,67 & $-1,45$ & 5.04 & 3,08 \\
$1996-2001$ & $-0,11$ & 0,91 & $-1,46$ & 0,44 \\
$1999-2004$ & $-5,72$ & 2,81 & $-9,31$ & 0,78 \\
$2002-2006$ & 8,98 & 0,50 & 1,94 & 6,54 \\
\hline
\end{tabular}

FONTE: Dados básicos do IBGE e CONAB (2006)

Verificando o comportamento do período tomado como um todo (1990-2006), observa-se que, assim como o Cerrado Mineiro, a região Sudoeste apresentou taxa de crescimento anual da produção positiva (2,59\% a.a.). A diferença é que ela apresentou, comparativamente, melhor resultado que o Cerrado. Esse crescimento da produção teve como fator principal o efeito composição ( $2,73 \%$ a.a.) e - menos importante, mas positivo - o efeito área (o,36\% a.a.). Como contrafator no período tem-se a queda do rendimento equivalente a 0,50\% a.a. (Tabela 5).

Os bons preços praticados a partir de 1994 contribuíram para o crescimento da produção na região (6,67\% a.a.) de 1993 a 1998. O destaque ficou para o efeito rendimento de 5,04\% ao ano, seguido do efeito composição de 3,08\% ao ano, sendo o efeito área o único negativo (-1,45\% ao ano). A evolução dos preços do café comercializado pela principal cooperativa da região Sudoeste, a COOXUPÉ, pode ser visualizada na Figura 2. 


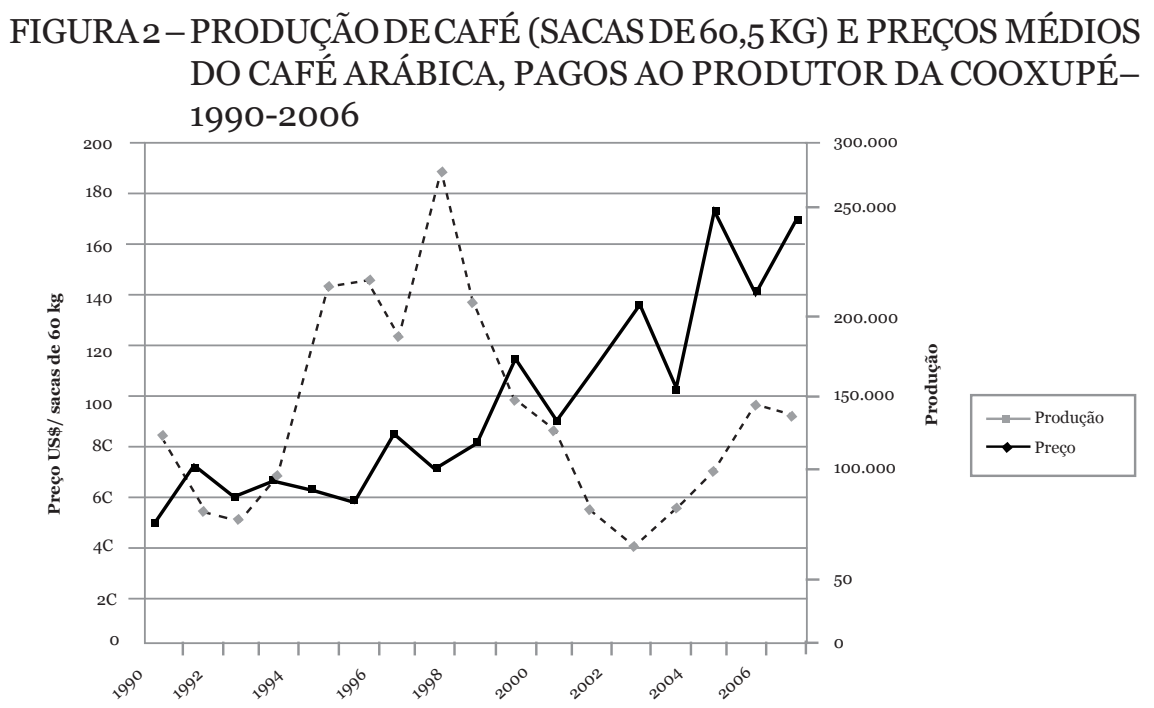

FONTE: Dados básicos da COOXUPÉ (2006)

Entre 2002 e 2006, a cafeicultura no Sudoeste apresentou efeitos área, rendimento e composição positivos (o,5\% a.a., 1,94\% a.a. e 6,54\% a.a. respectivamente) (Tabela 5), o que resultou em crescimento anual da produção de $8,98 \%$ ao ano. Nesse subperíodo, os preços do café comercializados pela COOXUPÉ cresceram, aproximadamente, $64 \%$, corroborando para esse bom desempenho da produção.

De 1999 a 2004, a taxa anual de crescimento na região Sudoeste apresentou seu menor índice $(-5,72 \%)$ em relação ao período estudado. $O$ efeito rendimento, responsável pelo péssimo desempenho da produção, teve queda de 9,31\% ao ano, o que pode ser justificado pela queda dos preços pagos aos produtores da região (Figura 2).

Na Tabela 6 são apresentados os resultados do efeito área dividido entre os efeitos escala e rendimento, considerando-se o período por completo e cinco subperíodos divididos entre 1990 e 2006. 
TABELA 6 - DECOMPOSIÇÃO DO EFEITO ÁREA EM EFEITOS ESCALA E SUBSTITUIÇÃO (HECTARES) - SUDOESTE DE MINAS

\begin{tabular}{cccc}
\hline & & EFEITO ÁREA & \\
\cline { 3 - 3 } PERÍODO & TOTAL & ESCALA & SUBSTITUIÇÃO \\
\hline $1990-2006$ & 181.416 & $19.370,14$ & $162.045,86$ \\
\hline $1990-1995$ & -40.312 & $-10.858,92$ & $-29.453,08$ \\
$1993-1998$ & 11.547 & $-22.002,48$ & $33.549,48$ \\
$1996-2001$ & 18.189 & $11.967,34$ & $6.221,65$ \\
$1999-2004$ & 52.775 & $35.700,51$ & $17.074,49$ \\
$2002-2006$ & 139.217 & $10.954,00$ & $128.262,00$ \\
\hline
\end{tabular}

FONTE: Dados básicos do IBGE e CONAB (2006)

Quando isolados os efeitos das demais fontes de crescimento - a saber, rendimento e composição - verifica-se que a área colhida de café aumentou em torno de 181.416 hectares entre 1990 e 2006 (Tabela 6). Destes, 19.370,14 decorreram da incorporação de novas áreas agrícolas, enquanto os demais (162.045,86 ha) foram provenientes da substituição de culturas, relativamente menos rentáveis, pelo café. Assim, pode-se afirmar que quase $90 \%$ do crescimento de área na cafeicultura do Sudoeste, no período, podem ser atribuídos ao efeito substituição.

Analisando o subperíodo 1990-1995, pode-se observar que a região Sudoeste teve efeito escala negativo e igual a -10.858,92 hectares, o que significa redução da área da cultura estudada. $O$ efeito substituição também foi negativo (-29.453,08 ha); isso mostra que durante o subperíodo considerado o café cedeu área para as demais culturas da região.

Nos quatro subperíodos seguintes (1993-1998, 1996-2001, 1999-2004 e 2002-2006), a área total de café no Sudoeste aumentou, o que proporcionou ganhos para a produção. O melhor resultado foi verificado entre 2002 e 2006, quando o efeito escala se mostrou positivo (10.954,00 ha), e aconteceu o mesmo com o efeito substituição (128.262,oo ha). Desse modo, verifica-se que no último subperíodo houve intenso movimento de substituição entre as culturas no Sudoeste, favorável à atividade cafeeira.

Continuando, os resultados encontrados para Minas Gerais e as regiões Cerrado e Sudoeste do estado fornecem subsídios para a formulação de algumas observações quanto ao comportamento futuro da cafeicultura mineira. 
Assim, quando analisado o comportamento das fontes de crescimento da cafeicultura e dos seus preços, ao longo do período estudado, fica evidente que os anos em que a produção de café apresentou taxas geométricas de crescimento positivas coincidiram com aqueles em que o preço do café estava em ascensão. Ademais, observa-se também que nesses períodos o efeito rendimento sempre respondia de forma imediata aos estímulos dos preços, enquanto o efeito área apresentou respostas mais defasadas.

Desse modo, espera-se que nos próximos anos as variações na produção de café, estimuladas pelo efeito rendimento, apresentem comportamento imediato e no mesmo sentido que as variações nos preços dessa commodity. Quanto às variações da produção atribuídas ao efeito área, acredita-se que essas apresentarão defasagem em relação às mudanças nos preços do café, isto é, as mudanças na produção só serão observadas anos depois.

\section{Conclusões}

Os resultados do estudo, referentes às fontes de crescimento do Estado, mostram que o cultivo de novas áreas e a substituição de outras culturas pelo café em áreas já utilizadas pela agricultura têm sido os principais fatores que influenciaram o crescimento da cultura no estado entre 1990 e 2006.

Os resultados para o Cerrado de Minas, entre 1990 e 2006, indicam crescimento da produção. Esse desempenho teve como principais fatores o acréscimo da área colhida e o aumento da produtividade, que compensaram os efeitos negativos causados na cafeicultura em decorrência da mudança na localização da cultura na região.

O aumento da produção de café no Cerrado Mineiro, creditado à expansão da área, tem acontecido principalmente mediante a incorporação de novas áreas agrícolas que, possivelmente, não estavam sendo utilizadas em atividades agrícolas e sim como pastagens nativas, reflorestamento ou, simplesmente, ficando em pousio.

Como era de se esperar, o efeito rendimento no Cerrado Mineiro foi maior que o apresentado pela região Sudoeste e pelo estado em quase todo o período estudado, ou seja, o elevado índice de tecnologia utilizado na cafeicultura irrigada do Cerrado confirmou a importância da produtividade no cultivo de café da região.

No Sudoeste, os resultados indicam que houve aumento na produção de café. Os responsáveis por esse fato foram os efeitos área e composição, ou seja, houve expansão da área cultivada e mudança na composição das culturas da região favoráveis à cafeicultura. 
O aumento da produção de café no Sudoeste, mediante o incremento da área, tem acontecido principalmente por meio do efeito substituição, isto é, a produção de café tem sido empregada para substituir outras culturas menos rentáveis na região.

Diante dos resultados apresentados, observa-se que os efeitos do processo de modernização podem gerar diferentes transformações, conforme as características das regiões estudadas. No caso do presente estudo, de modo geral, pôde-se observar que na região mais tradicional o crescimento da produção teve como fatores explicativos o aumento da área e, principalmente, a substituição de culturas menos rentáveis pelo café. Já na região relativamente mais moderna, os fatores explicativos foram o incremento da produtividade e a expansão da área cultivada com a cultura.

Assim, pode-se salientar que programas e políticas que visam o desenvolvimento agrícola de determinadas regiões devem levar em consideração as especificidades destas, de forma a estimular atividades e práticas agrícolas segundo suas necessidades e particularidades, gerando o melhor impacto possível para as mesmas.

\section{Referências}

ALMEIDA, P. N. A. (2003). Fontes de crescimento e sistema produtivo da orizicultura do Mato Grosso. Piracicaba: Tese de Doutorado em Economia Aplicada, Escola Superior de Agricultura Luiz Queiroz, Universidade de São Paulo.

ALVES, Lucio Rogério Aparecido \& SHIKIDA, Pery Francisco Assis (2001). "Fontes de crescimento das principais culturas do Estado do Paraná (1981-1989)." Revista Paranaense de Desenvolvimento 101(1): 32-17.

ARAÚJO, P. F. C. \& SCHUH, G. E. (1975). Desenvolvimento da agricultura: natureza do processo e modelos dualistas. São Paulo: Pioneira.

CIC (2007). "Dados históricos". Centro de Inteligência do Café. URL [On line]: http://www.cicbr.org.br. Acesso em: 30/1/2007.

CONAB (2006). "Indicadores agropecuários." Companhia Nacional de Abastecimento. URL [On line]: http://www.conab.gov.br. Acesso em: 10/8/2006.

COOXUPÉ (2006). "Preço histórico do café." Cooperativa Regional de Cafeicultores em Guaxupé Ltda. URL [On line]: http://www.cooxupe.com.br. Acesso em: 15/12/2006.

CURI, W. F. (1997). Eficiência e fontes de crescimento da agricultura mineira na dinâmica de ajustamento da economia brasileira. Viçosa: Tese de Doutorado em Economia Rural, Universidade Federal de Viçosa.

GOMES, M. F. M. (1990). Efeitos da expansão da produção de soja em duas regiões do Brasil. Viçosa: Tese Doutorado em Economia Rural, Universidade Federal de Viçosa.

GOMES, M. F. M. \& ROSADO, P. L. (2005). "Mudança na produtividade dos fatores de produção da cafeicultura nas principais regiões produtoras do Brasil." Revista de Economia e Sociologia Rural 43 (4): 633-656. 
HADDAD, P. R. \& ANDRADE, T. A. (1989). "Método de análise diferencial-estrutural". In: HADDAD, P. R. (Org.). Economia regional: teorias e métodos de análise. Fortaleza: BNB/ETENE, p. 249-286.

HAYAMI, Y. \& RUTTAN, V. W. (1988). Desenvolvimento agrícola: teoria e experiências internacionais. Brasília: Embrapa.

IBGE (2006). "Dados gerais.” Instituto Brasileiro de Geografia e Estatística. URL [On line]: http://www.sidra.igbe.gov.br. Acesso em: 25/12/2006.

IGREJA, Abel Ciro Minniti et al. (1983). "Análise quantitativa do desempenho da agricultura paulista, 1966-77.” Agricultura em São Paulo 7 (1): 117-157.

MENDES, A. G. \& FERNANDES, C. L. L. (1976). "Fontes de crescimento da produção agrícola, 1950-1970." Análise de Conjuntura 6 (2): 34-30.

MOREIRA, C. G. (1996). Fontes de crescimento das principais culturas do Rio Grande do Norte, 1981-92. Piracicaba: Dissertação de Mestrado em Economia Aplicada, Escola Superior de Agricultura Luiz Queiroz, Universidade de São Paulo.

RAMOS, P. (2005). “Questão agrária, salários, política agrícola e modernização da agropecuária brasileira.” In: RAMOS FILHO, L. O. \& ALY. JÚNIOR, O. (Org.). Questão agrária no Brasil: perspectiva histórica e configuração atual. São Paulo: INCRA, p.87-128.

SANTOS, F. A. et al. (2000). "Fatores associados à mudança da composição agrícola em duas regiões agrícolas em Minas Gerais.” In: 38. Congresso Brasileiro de Economia e Sociologia Rural, Anais... Rio de Janeiro, jul. 2000. CD-ROM.

SANTOS, V. E. (2005). A importância da produção e do processamento do café na economia mineira. Viçosa: Dissertação de Mestrado em Economia Aplicada, Universidade Federal de Viçosa.

ZOCKUN, M. H. G. P. (1978). A expansão da soja no Brasil: alguns aspectos de produção. São Paulo: Dissertação de Mestrado em Economia, Universidade de São Paulo.

Submissão: 1 de março de 2007

Primeira resposta: 15 de março de 2007

Aceite: 4 de maio de 2007 